\title{
Validity of the Shahin Mixed Depression Scale: A Self-Rated Instrument Designed to Measure the Non-DSM Mixed Features in Depression
}

This article was published in the following Dove Press journal: Neuropsychiatric Disease and Treatment

\author{
Islam Shahin (D) \\ Caterina Del Mar Bonnin ${ }^{2}$ \\ Elsayed Saleh ${ }^{3}$ \\ Khaled Helmy (D) ${ }^{4,5}$ \\ Usama M Youssef ${ }^{6}$ \\ Eduard Vieta ${ }^{2}{ }^{2}$ \\ 'Cairo Mood Center, Cairo, Egypt; \\ ${ }^{2}$ Barcelona Bipolar Disorders and \\ Depressive Unit, Hospital Clinic, Institute \\ of Neuroscience, University of Barcelona, \\ IDIBAPS, CIBERSAM, Barcelona, \\ Catalonia, Spain; ${ }^{3}$ Department of \\ Psychiatry, Mansoura University, \\ Mansoura, Egypt; ${ }^{4}$ Training and Research \\ Unit, New Nozha Hospital, Alexandria, \\ Egypt; ${ }^{5}$ Ciconia Recovery London (CRL), \\ London, UK; ${ }^{6}$ Department of Psychiatry, \\ Zagazig University, Zagazig, Egypt
}

\section{Video Abstract}

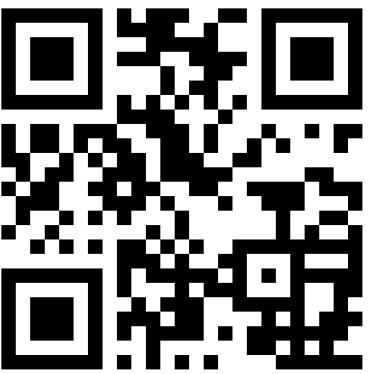

Point your SmartPhone at the code above. If you have a $Q R$ code reader the video abstract will appear. Or use: https://youtu.be/BkB7]6Nnz0E

Correspondence: Islam Shahin Tel +20II 50759876

Email ishahin10@yahoo.com
Background: The DSM5-defined mixed features in depression do not include psychomotor agitation, irritability or distractibility because they are considered overlapping symptoms. A growing number of modern psychiatrists have expressed dissatisfaction with this and proposed alternative sets of mixed symptoms that are much more common and clinically relevant. Among such alternative criteria were those proposed by Koukopoulos. He utilized the research diagnostic criteria of agitated depression (RDC-A) as a mixed depression subtype, and validated another form of mixed depression, the Koukopoulos criteria for mixed depression (K-DMX).

Purpose: This study provides psychometric validation for the first self-rated scale designed to measure the most common mixed symptoms in depression as proposed by Koukopoulos. Patients and Methods: We conducted a multicenter cross-sectional study of 170 patients with unipolar depression. They completed the Shahin Mixed Depression Scale (SMDS) and underwent expert interviews as a gold standard reference. SMDS' psychometric properties were assessed, including Cronbach's alpha, factor analysis, sensitivity, specificity, predictive value and accuracy.

Results: We found significant association and agreement between mixity according to SMDS and the gold standard (K-DMX and RDC-A according to expert interview) with good internal consistency (Cronbach's alpha $=0.87$ ), high sensitivity $(=91.4 \%)$, specificity $(=98.0 \%)$, positive predictive value $(=96.9 \%)$, negative predictive value $(=94.2 \%)$ and accuracy $(=95.2 \%)$. Factor analysis identified one factor for psychomotor agitation and another for mixity without psychomotor agitation.

Conclusion: SMDS was a reliable and valid instrument for assessing the frequently encountered and clinically relevant mixed features in depression.

Keywords: mixed depression, mixed depression scale, major depressive disorder, psychomotor agitation, agitated depression, unipolar depression

\section{Introduction}

Irritability, psychomotor agitation and distractibility were considered overlapping symptoms and excluded from the DSM-5 definition of mixed depression (DMX). ${ }^{1}$ Such a definition is poorly adjusted to the reality. Moreover, there is no mention in the earlier scientific literature of the DSM5-defined mixed symptoms (excluding pressured speech and flight of ideas). ${ }^{2}$

Including the overlapping symptoms, and psychomotor agitation is one of them, recent studies have reported a high prevalence of mixed depression both in samples of patients with bipolar disorder (BD) and major depressive disorder (MDD); for 
instance, Koukopoulos et $\mathrm{al}^{3}$ reported a prevalence of $27 \%$ with both of their definitions of mixed depression (i.e. either motor or psychic agitated depression) among 361 patients with bipolar and unipolar depression. In the same line, Maj et $\mathrm{al}^{4}$ found $19.5 \%$ agitated depression defined by the research diagnostic criteria ${ }^{5}$ (RDC) in 313 patients with BD. Benazzi, ${ }^{6}$ defining a mixed depressive state as a major depressive episode plus three or more hypomanic symptoms, including psychomotor agitation, irritability and distractibility, reported a prevalence of $43.9 \%$ among 144 patients with unipolar depression (UP) and $218 \mathrm{BD}$ type II patients. In the study of Takeshima and Oka, ${ }^{7}$ psychomotor agitation is the most frequently observed hypo/manic symptom in both patients with BD (59.8\%) and those with MDD (48.8\%).

Moreover, a growing number of contemporary psychiatrists have expressed dissatisfaction with the DSM-5 in considering psychomotor agitation as just a part of a subcriterion of major depression, proposing agitated depression as a mixed form of mood disorders. ${ }^{3,8-15}$

So, alternative diagnostic criteria of mixed depression have been proposed. They focused on the most common mixed symptoms, including psychomotor agitation, distractibility, irritability, racing/crowded thoughts, anger, increased talkativeness, indecisiveness, anxiety, emotional lability/tearfulness, inner tension, rumination, initial or middle insomnia, impulsivity and risky behaviors. ${ }^{16}$

One alternative set of mixed symptoms was proposed by Koukopoulos. ${ }^{2}$ He recommended giving the name agitated depression to mixed depression with psychomotor agitation as defined by the research diagnostic criteria (RDC-A): the presence of at least two of the following manifestations of psychomotor agitation (not mere subjective anxiety) for several days during the current episode: pacing; hand wringing; unable to sit still; pulling or rubbing on hair, skin, clothing, or other objects; outburst of complaining or shouting; and over-talkativeness. ${ }^{5}$

$\mathrm{He}$ also proposed the name mixed depression (K-DMX) for mixed depression without psychomotor agitation when at least three of the following symptoms are present along with MDD: inner tension/agitation, racing or crowded thoughts, irritability or unprovoked feeling of rage, absence of signs of retardation, talkativeness, dramatic description of suffering or frequent spells of weeping, mood lability and marked emotional reactivity, and early insomnia. In his explanation, he believed that the origin of psychic pain, agitation and other mixed symptoms in depression is an underlying excitatory process. ${ }^{8}$
The specific diagnostic criteria for mixed depression without psychomotor agitation (K-DMX) have already been validated by a prior work by Sani et al. ${ }^{17}$

Although mixed depression with psychomotor agitation, i.e. agitated depression (RDC-A) has yet to be validated as a mixed depression subtype, it seems to have diagnostic utility. ${ }^{18}$ Such a diagnostic utility could be related to its impact on treatment. ${ }^{19,20}$

Agitated depression (RDC-A) responds well to lowdose neuroleptics, lithium, anticonvulsants and electroconvulsive therapy, whereas it shows marked deterioration in the patient's condition in response to antidepressants, ${ }^{21-23}$ in the form of increased agitation, insomnia, greater suffering and the emergence of psychotic symptoms and suicidal ideas and impulses.

Based on the validity of $\mathrm{K}-\mathrm{DMX}^{17}$ and the clinical utility of RDC-A as a mixed depression subtype, ${ }^{18-20}$ the aim of this study is to evaluate the psychometric properties of the Shahin Mixed Depression Scale (SMDS) in measuring the non-DSM, Koukopoulos-defined mixed features in depression in a sample of patients with unipolar depression.

\section{Materials and Methods Study Settings}

The study was conducted at the outpatient psychiatric clinic of Mansoura University Hospital, at the Shahin private mood clinic in Cairo, and the outpatient clinic of a private mental hospital in Alexandria.

The sample size was calculated through Epi-Info (Epidemiological information package) software version 6.1, according to the following collected data, taking into account that the frequency of the proposed non-DSM mixed depression is $33 \%-47 \%$ as reported by some studies, ${ }^{24,25}$ with a confidence level $95 \%$ and a degree of precision $80 \%$. The sample was 170 , taken by systematic randomization.

\section{Participants}

A total of 170 consecutive patients (off drugs for at least 2 weeks) with unipolar depressive disorder (UP) were randomly enrolled in the study from July 1, 2019 to September 30, 2019. Their proportional allocation was as follows: 74 from Mansoura clinic, 68 from Shahin mood clinic and 28 from Alexandria clinic.

\section{Inclusion Criteria}

Patients with unipolar depression (UP), aged 19-65 years and diagnosed by clinical interview following DSM-5 
criteria were included in the study. Montgomery-Asberg Depression Rating Scale (MADRS) ${ }^{26}$ was used to assess depressive symptoms. A score of 20 or greater had to be met for a clinical depressive episode. Hypomania Interview Guide-Current assessment Version (HIGH-C) ${ }^{27}$ was used to test for significant concurrent hypo/manic symptoms. A score less than 8 was required for patients with UP to be included in the study, following Benazzi's dimensional definition of mixed depression. ${ }^{28}$

\section{Exclusion Criteria}

To avoid confounding evaluation of the clinical picture, substance-related disorders, borderline personality disorder, psychotic symptoms, adult ADHD, dementia, mental retardation and intra-depressive hypo/manic symptoms mounting to DSM5-defined mixed depression diagnosis were excluded from the study (diagnosed by clinical interview following DSM-5 criteria). Illiterate patients and patients with unstable or severe general medical conditions were also excluded.

\section{Ethical Considerations}

Official permission was obtained from Institutional Review Board (IRB) of Mansoura University. A verbal consent was obtained from the study group. It was informed verbal consent. The verbal consent process was approved by the IRB of Mansoura University. Our study complied with the Declaration of Helsinki.

\section{Shahin Mixed Depression Scale (SMDS)}

The SMDS is a self-rated screening test comprising two parts. The first part (items 1-6) represents psychomotor agitation as defined by the research diagnostic criteria ${ }^{5}$ with a cutoff score greater than or equal to 2 . The other subscale (items 6-13) matched Koukopoulos mixed features K-DMX as validated by Koukopoulos and collaborators ${ }^{17}$ with a cutoff score greater than or equal to 3. Of note, item no. 6 i.e. over-talkativeness, was shared by both subscales and could then be included in either context. Items no. 8 (racing or crowded thoughts), no. 9 (subjective or objective irritability), no. 10 (dramatic description of suffering or frequent spells of weeping), and no. 11 (early or middle insomnia) were further subdivided into two sub-items ( $a$ and b). Checking "Yes" to either ( $a$ or $b$ ) was considered a positive score. As there might be an overlap between depressive anxiety and inner tension, ${ }^{21}$ we wanted to better clarify item no. 7, which represented inner tension. We further subdivided it into three sub-items (a, b, and c) and for a positive score, a or b plus c had to be checked "Yes". Item no. 13 (representing signs of retardation) was also subdivided into two subitems ( $\mathrm{a}$ and $\mathrm{b}$ ). For a positive score, both sub-items (a and b) had to be checked "No". For the remaining items, checking "Yes" to any of them was considered a positive score (Appendix).

The original English version was administered to a convenience group of English-speaking British patients with mood disorders to assess feasibility and face validity. The items were then revised on the basis of this experience and a final version was approved by the authors. The English version was translated into Arabic. Back translation was performed by a bilingual psychiatrist unaware of the original SMDS. A preliminary translated version was administered to 50 Arabic patients with mood disorders. The Arabic authors of the present study reviewed the results of this preliminary investigation, and a final version was approved by them. It was considered equivalent to the original English version.

\section{The Gold Standard}

As it was the first scale of its kind and there was no gold standard with which to correlate, SMDS was validated against expert interviews as a gold reference standard. These interviews were carried out by senior psychiatrists with a minimum of 20 years of experience. They were blind to SMDS results. The experts used a semi-structured interview based on the SCID for DSM-5 (SCID-5) for symptoms such as over-talkativeness and racing thoughts.

For symptoms not found in the SCID-5, supplementary definitions were given: For psychomotor agitation, some questions were taken from Koukopoulos Mixed Depression Rating Scale KMDRS:" "Have you been so fidgety and restless that you couldn't sit still? Do you have to keep pacing up and down?", and we added others, following the RDC definition: "Have you kept wringing your hands, pulling or rubbing on your hair, skin or clothes? Have you had outbursts of complaining or shouting?"

For inner agitation (tension), patients had to score 3 on KMDRS item no. $9 .^{29}$

For crowded thoughts, we followed Koukopoulos' definition, i.e. the patient complains of the stream rather than the content: "Have you felt your head full of thoughts that you were unable to stop?"

Crowded thoughts should be differentiated from depressive ruminations which are few, and the patient suffers from the thought content rather than the stream. 
For subjective feelings of unprovoked rage, the patient had to score 2 or 3 on KMDRS item no. $6 .^{29}$

For objective expression of irritability, we followed KMDRS corresponding instruction no. 7: Rate overt expressions of irritability, annoyance and anger, including being argumentative, shouting, losing temper, as well as throwing things and being assaultive.

For dramatic description of suffering or frequent spells of weeping, patients had to score 2 or 3 on KMDRS.

For initial insomnia, the required score was at least 1 on the corresponding KMDRS item no. 11, and we followed the KMDRS instruction no. 11 in defining middle insomnia: Only waking up with agitation and/or difficulty falling back to sleep should be rated.

For mood lability, patients should score 3 on the corresponding KMDRS item no. 4.

For the definition of retardation, we followed the instructions of The Cornell Scale for Depression in Dementia CSDD $:^{30}$ Retardation is characterized by slow speech, delayed response to questions and decreased motor activity and/or reactions, and we made a small change to the question: "Have you been talking or moving more slowly than is normal for you?"

\section{Statistical Analysis}

Data were collected by expert interviews, previous history and scales. Data were then imported into Statistical Package for the Social Sciences (SPSS version 20.0) software. Qualitative data were represented as number and percentage. Quantitative continuous data were represented by their means and standard deviations. The following are the tests used to assess significant differences:

1. Chi squared tests $\left(X^{2}\right)$ to assess difference and association of qualitative variables.

2. $t$-Tests to assess differences between quantitative continuous data. Agreement was tested by Kappa agreement. Significant probability was less than or equal to 0.05 $(\mathrm{P} \leq 0.05)$. We established a factor analysis to determine the extent to which shared variance exists among SMDS variables within the pool of items.

\section{Results}

\section{Socio-Demographic Data}

We studied 170 patients with a mean age of $31.04 \pm 8.12$, with minimum 19 and maximum $65 ; 44.1 \%$ were male and $55.9 \%$ were female. A positive family history of bipolar disorder was found in $22.9 \%$, as shown in Table 1.
Table I Demographic and Clinical Characteristics of the Sample

\begin{tabular}{|c|c|c|c|}
\hline Age & $\begin{array}{l}\text { Mean } \pm \text { SD } \\
\text { Median (range) }\end{array}$ & \multicolumn{2}{|c|}{$\begin{array}{l}31.04 \pm 8.12 \\
31.0(19-65)\end{array}$} \\
\hline Onset & $\begin{array}{l}\text { Mean } \pm \text { SD } \\
\text { Median (range) }\end{array}$ & \multicolumn{2}{|c|}{$\begin{array}{l}13.28 \pm 8.4 \\
17.0(I-29)\end{array}$} \\
\hline $\begin{array}{l}\text { Duration of index } \\
\text { MDE }\end{array}$ & $\begin{array}{l}\text { Mean } \pm \text { SD } \\
\text { Median (range) }\end{array}$ & \multicolumn{2}{|c|}{$\begin{array}{l}13.62 \pm 10.8 \\
4.0(2-55)\end{array}$} \\
\hline & & $\mathrm{N}$ & $\%$ \\
\hline Sex & $\begin{array}{l}\text { Male } \\
\text { Female }\end{array}$ & $\begin{array}{l}75 \\
95\end{array}$ & $\begin{array}{l}44.1 \\
55.9\end{array}$ \\
\hline Residence & $\begin{array}{l}\text { Urban } \\
\text { Rural }\end{array}$ & $\begin{array}{l}83 \\
87\end{array}$ & $\begin{array}{l}48.8 \\
51.2\end{array}$ \\
\hline Occupation & $\begin{array}{l}\text { Unemployed } \\
\text { Employed }\end{array}$ & $\begin{array}{l}60 \\
110\end{array}$ & $\begin{array}{l}35.3 \\
64.7\end{array}$ \\
\hline Marital status & $\begin{array}{l}\text { Single } \\
\text { Married } \\
\text { Divorced } \\
\text { Widow }\end{array}$ & $\begin{array}{l}43 \\
38 \\
78 \\
11\end{array}$ & $\begin{array}{l}25.3 \\
22.4 \\
45.9 \\
6.5\end{array}$ \\
\hline Education & $\begin{array}{l}\text { Primary } \\
\text { Preparatory and secondary } \\
\text { High }\end{array}$ & $\begin{array}{l}70 \\
88 \\
12\end{array}$ & $\begin{array}{l}41.2 \\
51.7 \\
7.1\end{array}$ \\
\hline Family history & $\begin{array}{l}-\mathrm{VE} \\
+\mathrm{VE}\end{array}$ & $\begin{array}{l}131 \\
39\end{array}$ & $\begin{array}{l}77.1 \\
22.9\end{array}$ \\
\hline
\end{tabular}

Abbreviations: MDE, major depressive episode; SD, standard deviation; +VE, positive; -VE, negative.

\section{Frequencies and Symptom Endorsements}

Regarding RDC-A, the highest symptom endorsement was RDC2 (Inability to sit still), the lowest symptom endorsement was RDC6 (Over-talkativeness) and overall RDC-A was present in $18.2 \%$, as shown in Figure 1. Regarding K-DMX, the highest symptom endorsement was DMX1 (Absence of signs of retardation), the lowest symptom endorsement was DMX2 (Over-talkativeness) and overall K-DMX was present in $22.9 \%$, as shown in Figure 2. Regarding SMDS items, the highest item endorsement was item no. 12 (Mood lability) and the lowest was item no. 3 (Hand wringing). Pure depression according to SMDS was $61.2 \%$ and mixed depression was $38.8 \%$, as shown in Table 2 .

\section{Internal Consistency}

SMDS demonstrated high reliability, and internal consistency was good (Cronbach's Alpha=0.87).

\section{Factor Analysis}

A confirmatory factor analysis identified two components: a factor for mixity without psychomotor agitation and 
RDC-A

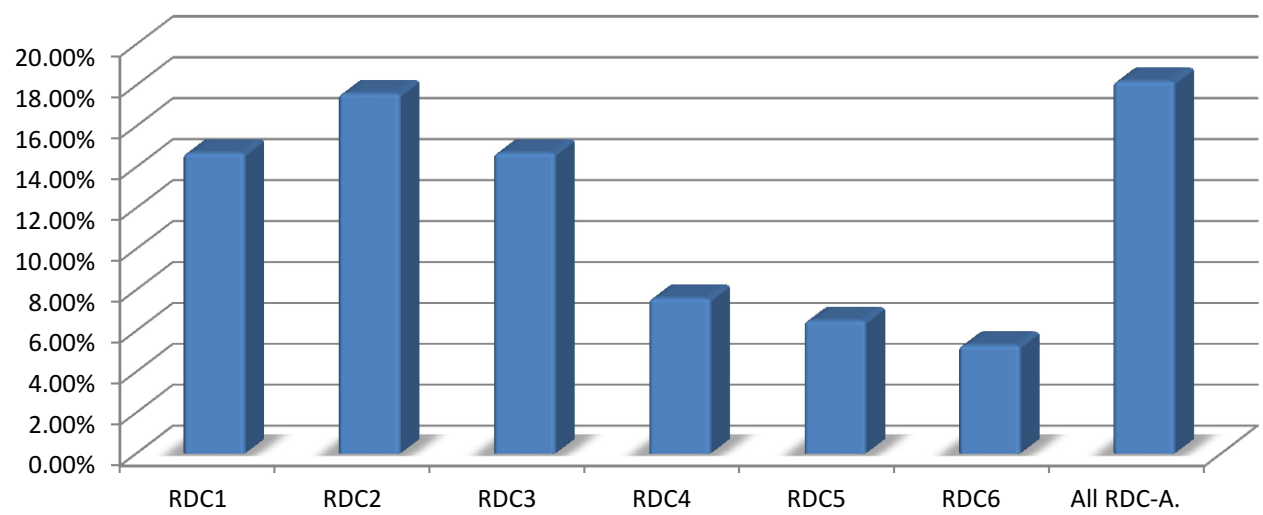

Figure I RDC-A distribution among studied group.

Notes: RDC1: pacing. RDC2: inability to sit still. RDC3: hand wringing. RDC4: pulling or rubbing on hair, skin or clothing. RDC5: outbursts of complaining or shouting. RDC6: over talkativeness.

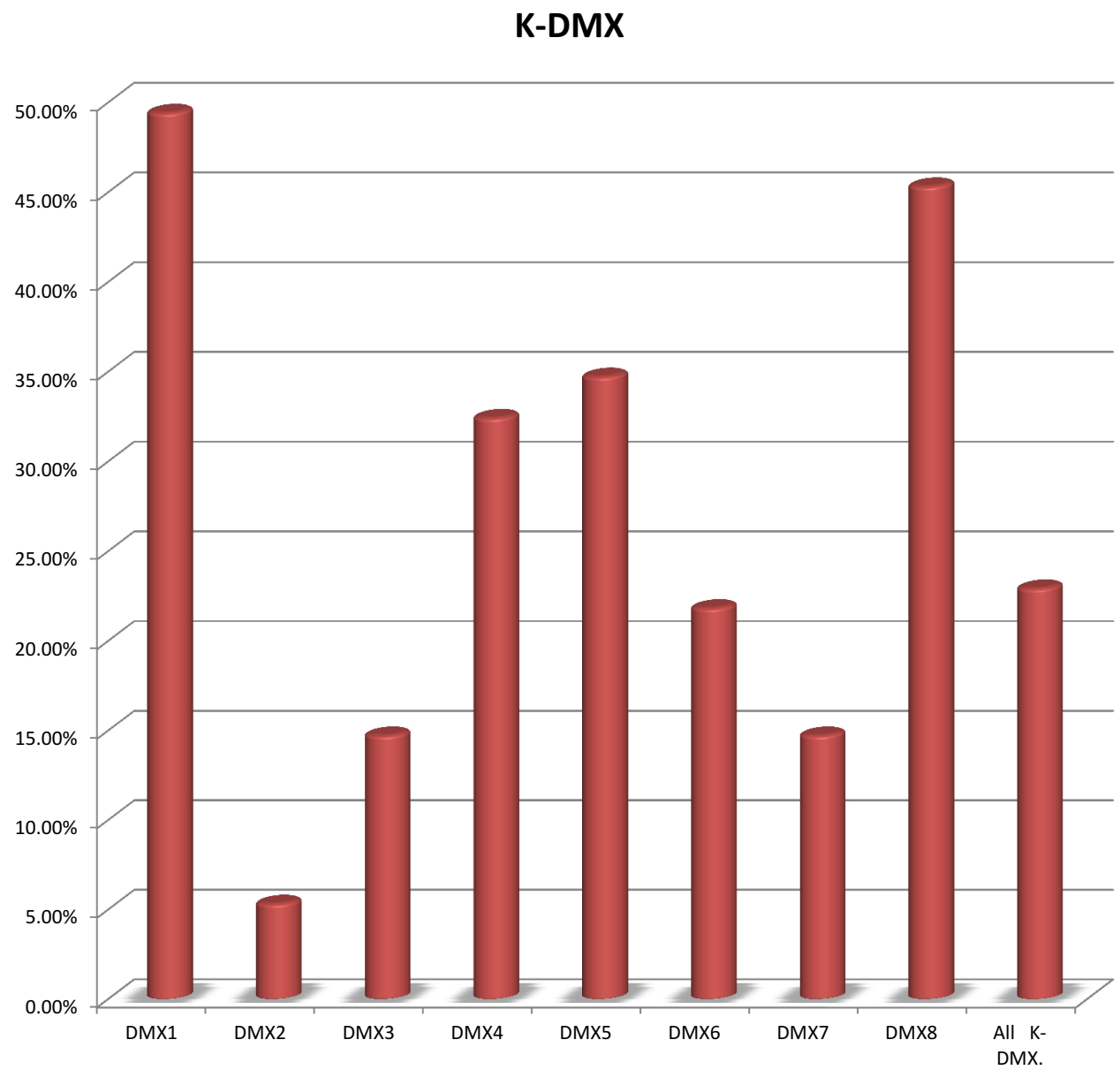

Figure 2 K-DMX distribution among studied group.

Notes: DMXI: absence of retardation. DMX2: over talkativeness. DMX3: psychic agitation or inner tension. DMX4: dramatic description of suffering or frequent spells of weeping. DMX5: racing/crowded thoughts. DMX6: irritability or unprovoked rage. DMX7: mood lability and marked reactivity. DMX8: early or middle insomnia.

a factor for psychomotor agitation. From item 7 to item 13, each item accounted for smaller and smaller amounts of the total variance, and items nos. 1, 2, 3, 4, 5, 6 and 13 were related to both factors but more to agitation. Items nos. 8 and 12 were related only to mixity, and items nos. 7, 9, 10 and 11 were related to both factors but more to mixity. 
Table 2 SMDS Item Distribution and Related Diagnosis

\begin{tabular}{|c|c|c|c|c|}
\hline & & & $\mathbf{N}$ & $\%$ \\
\hline $\begin{array}{l}\text { Agitated } \\
\text { depression } \\
\text { Mixed } \\
\text { depression }\end{array}$ & $\begin{array}{l}\text { Item no. I, } \\
\text { Inability to sit still } \\
\text { Item no. } 2 \text {, } \\
\text { Pacing } \\
\text { Item no. 3, } \\
\text { Hand wringing } \\
\text { Item no. 4, } \\
\text { Pulling or rubbing on hair, } \\
\text { skin or clothing } \\
\text { Item no. 5, } \\
\text { Outbursts of complaining } \\
\text { or shouting } \\
\text { Item no. } 6, \\
\text { Over-talkativeness } \\
\text { Item no. } 7, \\
\text { Psychic agitation } \\
\text { Item no. } 8, \\
\text { Racing/crowded thoughts } \\
\text { Item no. 9, } \\
\text { Irritability or unprovoked } \\
\text { rage } \\
\text { Item no. I0, } \\
\text { Dramatic description of } \\
\text { suffering or frequent spells } \\
\text { of weeping } \\
\text { Item no. II, } \\
\text { Early or middle insomnia } \\
\text { Item no. I2, } \\
\text { Mood lability } \\
\text { Item no. I3, } \\
\text { Absence of retardation }\end{array}$ & $\begin{array}{l}\text { Negative } \\
\text { Positive } \\
\text { Negative } \\
\text { Positive } \\
\text { Negative } \\
\text { Positive } \\
\text { Negative } \\
\text { Positive } \\
\text { Negative } \\
\text { Positive } \\
\text { Negative } \\
\text { Positive } \\
\text { Negative } \\
\text { Positive } \\
\text { Negative } \\
\text { Positive } \\
\text { Negative } \\
\text { Positive } \\
\text { Negative } \\
\text { Positive } \\
\text { Positive } \\
\text { Negative } \\
\text { Positive } \\
\text { Pegative } \\
\text { Positive }\end{array}$ & $\begin{array}{l}151 \\
19 \\
133 \\
37 \\
114 \\
56 \\
126 \\
44 \\
129 \\
41\end{array}$ & $\begin{array}{l}65.9 \\
34.1 \\
78.2 \\
21.8 \\
91.2 \\
8.8 \\
85.9 \\
14.1 \\
\\
85.9 \\
14.1 \\
\\
88.8 \\
11.2 \\
78.2 \\
21.8 \\
67.1 \\
32.9 \\
74.1 \\
25.9 \\
75.9 \\
24.1\end{array}$ \\
\hline \multirow[t]{2}{*}{ Diagnosis } & \multicolumn{2}{|l|}{$\begin{array}{l}\text { Pure depression } \\
\text { Mixity } \\
\text { Agitation }\end{array}$} & $\begin{array}{l}104 \\
35 \\
31\end{array}$ & $\begin{array}{l}61.2 \\
20.6 \\
18.2\end{array}$ \\
\hline & Overall & $\begin{array}{l}\text { Not } \\
\text { mixed } \\
\text { Mixed } \\
\text { Total }\end{array}$ & $\begin{array}{l}66 \\
170\end{array}$ & $\begin{array}{l}61.2 \\
38.8 \\
100.0\end{array}$ \\
\hline
\end{tabular}

\section{Association Between Mixity and Demographic Characteristics}

There were significantly more mixed cases in later age: mixed group $35.66 \pm 10.25$ and pure depression group $28.11 \pm 4.42$. The mixed group was further significantly associated with being single and with primary and high education levels. It was also significantly associated with a positive family history of bipolar disorder and moderate CGI. However, there was no significant association with sex, residence or occupation, as shown in Table 3.

\section{Validity of SMDS}

We found significant association and agreement between mixity according to SMDS and the gold standard (K-DMX according to expert interview) with sensitivity $87.1 \%$, specificity $99.2 \%$, +VE predictive $97.1 \%,-\mathrm{VE}$ predictive $96.2 \%$ and accuracy $96.4 \%$. Also, we found significant association and agreement between agitation according to SMDS and the gold standard (RDC-A according to expert interview) with sensitivity $96.8 \%$, specificity $99.3 \%,+\mathrm{VE}$ predictive $96.7 \%$, -VE predictive $99.2 \%$ and accuracy $98.8 \%$. Regarding overall mixity, we found significant association and agreement between overall mixity according to SMDS and the gold standard with sensitivity $91.4 \%$, specificity $98.0 \%$, +VE predictive $96.9 \%,-$ VE predictive $94.2 \%$ and accuracy $95.2 \%$ as shown in Table 4 .

\section{Discussion}

This is the second study assessing, in an outpatient sample, the validity of SMDS, a self-rated screening instrument designed to measure the non-DSM mixed features in depression, as proposed by Koukopoulos. Against an expert interview diagnosis of the clinically valid Koukopoulos criteria K-DMX, and of the clinically utilized research diagnostic criteria of agitated depression RDC-A, which is used as the "gold standard", the sensitivity against RDC-A was $96.8 \%$ and the specificity was $99.3 \%$; the sensitivity against K-DMX was $87.1 \%$ and the specificity was $99.2 \%$. Factor analysis identified two components that capture the proposed mixed features: a factor for psychomotor agitation and a factor for mixity without psychomotor agitation. In our study, we found that SMDS had good reliability and internal consistency (Cronbach's Alpha $=0.87$ ). We also found that mixed states were significantly more frequent in later age. This finding is in line with some studies ${ }^{31}$ but contradicts others., ${ }^{42-35}$

Our aim in this, as in our earlier investigation ${ }^{36}$ was to include only patients with unipolar depression. This may account for the higher age finding. It is essential to note that in patients with non-DSM mixed features, bipolar latency is not the only important consideration. The more practical and clinically relevant negative impact of antidepressant treatment, irrespective of any actual switch to frank hypo/mania, must also be borne in mind. Of note, as reported, ${ }^{32,34,35,37-39}$ there was more positive family history of bipolar disorder in cases with mixed depression.

This is the first self-rated scale of its kind that addresses the most common non-DSM mixed features as proposed by 
Table 3 Basic Demographic and Clinical Data Distribution Among Pure Depression and Mixed Groups

\begin{tabular}{|c|c|c|c|c|c|c|}
\hline & & & \multicolumn{2}{|l|}{ Group } & \multirow{3}{*}{$\begin{array}{l}x^{2} \\
-6.612\end{array}$} & \multirow[t]{2}{*}{$\mathbf{P}$} \\
\hline & & & Pure Depression & Mixed & & \\
\hline Age & \multicolumn{2}{|l|}{ Mean \pm SD } & $28.11 \pm 4.42$ & $35.66 \pm 10.25$ & & $0.00 * *$ \\
\hline \multirow[t]{2}{*}{ Sex } & Male & $\begin{array}{l}N \\
\%\end{array}$ & $\begin{array}{l}52 \\
50.0\end{array}$ & $\begin{array}{l}23 \\
34.8\end{array}$ & \multirow[t]{2}{*}{3.76} & \multirow[t]{2}{*}{0.053} \\
\hline & Female & $\begin{array}{l}N \\
\%\end{array}$ & $\begin{array}{l}52 \\
50.0\end{array}$ & $\begin{array}{l}43 \\
65.2\end{array}$ & & \\
\hline \multirow[t]{2}{*}{ Residence } & Rural & $\begin{array}{l}N \\
\%\end{array}$ & $\begin{array}{l}46 \\
44.2\end{array}$ & $\begin{array}{l}37 \\
56.1\end{array}$ & \multirow[t]{2}{*}{2.26} & \multirow[t]{2}{*}{0.13} \\
\hline & Urban & $\begin{array}{l}N \\
\%\end{array}$ & $\begin{array}{l}58 \\
55.8\end{array}$ & $\begin{array}{l}29 \\
43.9\end{array}$ & & \\
\hline \multirow[t]{2}{*}{ Occupation } & Employed & $\begin{array}{l}N \\
\%\end{array}$ & $\begin{array}{l}41 \\
39.4\end{array}$ & $\begin{array}{l}19 \\
28.8\end{array}$ & \multirow[t]{2}{*}{2.69} & \multirow[t]{2}{*}{0.18} \\
\hline & Unemployed & $\begin{array}{l}N \\
\%\end{array}$ & $\begin{array}{l}63 \\
60.6\end{array}$ & $\begin{array}{l}47 \\
71.2\end{array}$ & & \\
\hline \multirow[t]{4}{*}{ Marital status } & Single & $\begin{array}{l}N \\
\%\end{array}$ & $\begin{array}{l}20 \\
19.2\end{array}$ & $\begin{array}{l}23 \\
34.8\end{array}$ & \multirow[t]{4}{*}{15.55} & \multirow[t]{4}{*}{$0.001 * *$} \\
\hline & Married & $\begin{array}{l}N \\
\%\end{array}$ & $\begin{array}{l}32 \\
30.8\end{array}$ & $\begin{array}{l}6 \\
9.1\end{array}$ & & \\
\hline & Divorced & $\begin{array}{l}N \\
\%\end{array}$ & $\begin{array}{l}43 \\
41.3\end{array}$ & $\begin{array}{l}35 \\
53.0\end{array}$ & & \\
\hline & Widow & $\begin{array}{l}N \\
\%\end{array}$ & $\begin{array}{l}9 \\
8.7\end{array}$ & $\begin{array}{l}2 \\
3.0\end{array}$ & & \\
\hline \multirow[t]{3}{*}{ Education } & Primary & $\begin{array}{l}N \\
\%\end{array}$ & $\begin{array}{l}20 \\
19.2\end{array}$ & $\begin{array}{l}50 \\
75.8\end{array}$ & \multirow[t]{3}{*}{88.41} & \multirow[t]{3}{*}{$0.00 * *$} \\
\hline & Preparatory and secondary & $\begin{array}{l}N \\
\%\end{array}$ & $\begin{array}{l}84 \\
80.8\end{array}$ & $\begin{array}{l}4 \\
6.1\end{array}$ & & \\
\hline & High & $\begin{array}{l}N \\
\%\end{array}$ & $\begin{array}{l}0 \\
0.0\end{array}$ & $\begin{array}{l}12 \\
18.2\end{array}$ & & \\
\hline \multirow[t]{2}{*}{ Family history of bipolar disorder } & No & $\begin{array}{l}N \\
\%\end{array}$ & $\begin{array}{l}94 \\
90.4\end{array}$ & $\begin{array}{l}37 \\
56.1\end{array}$ & \multirow[t]{2}{*}{26.9} & \multirow[t]{2}{*}{$0.00 * *$} \\
\hline & Yes & $\begin{array}{l}N \\
\%\end{array}$ & $\begin{array}{l}10 \\
9.6\end{array}$ & $\begin{array}{l}29 \\
43.9\end{array}$ & & \\
\hline \multirow[t]{2}{*}{ CGI } & Mild & $\begin{array}{l}N \\
\%\end{array}$ & $\begin{array}{l}54 \\
51.9\end{array}$ & $\begin{array}{l}15 \\
22.7\end{array}$ & \multirow[t]{2}{*}{14.27} & \multirow[t]{2}{*}{$0.00 * *$} \\
\hline & Moderate & $\begin{array}{l}N \\
\%\end{array}$ & $\begin{array}{l}50 \\
48.1\end{array}$ & $\begin{array}{l}51 \\
77.3\end{array}$ & & \\
\hline \multicolumn{2}{|l|}{ Total } & $\begin{array}{l}N \\
\%\end{array}$ & $\begin{array}{l}104 \\
100.0\end{array}$ & $\begin{array}{l}66 \\
100.0\end{array}$ & & \\
\hline
\end{tabular}

Note: **Highly significant.

Koukopoulos. The Koukopoulos Mixed Depression Rating Scale $(\mathrm{KMDRS})^{29}$ is a clinician-rated scale that captures the same construct. However, for a busy clinician, it might be time consuming to use it on a regular basis. Another clinician-rated bivariate scale for both manic and depressive mixed features has been developed by Cavanagh et al. ${ }^{40}$ 
Table 4 Association, Agreement and Validity of SMDS

\begin{tabular}{|c|c|c|c|c|c|c|c|}
\hline & & & \multicolumn{2}{|c|}{$\begin{array}{l}\text { K-DMX According to Expert } \\
\text { Interview }\end{array}$} & \multirow[t]{2}{*}{$\chi^{2}$} & \multirow[t]{2}{*}{$\mathbf{P}$} & \multirow[t]{2}{*}{ Kappa Agreement } \\
\hline & & & -VE & +VE & & & \\
\hline \multirow[t]{4}{*}{ Mixity according to SMDS } & \multirow[t]{2}{*}{$-\mathrm{VE}$} & $\mathrm{N}$ & 130 & 5 & \multirow[t]{4}{*}{124.5} & \multirow[t]{4}{*}{$0.00 * *$} & \multirow[t]{4}{*}{0.82} \\
\hline & & $\%$ & 99.2 & 12.9 & & & \\
\hline & \multirow[t]{2}{*}{$+V E$} & $\mathrm{~N}$ & 1 & 34 & & & \\
\hline & & $\%$ & 0.8 & 87.1 & & & \\
\hline \multicolumn{2}{|l|}{ Total } & $\mathrm{N}$ & 131 & 39 & & & \\
\hline \multirow{2}{*}{\multicolumn{3}{|c|}{ Validity }} & Sensitivity & Specificity & +VE Predictive & -VE Predictive & Accuracy \\
\hline & & & $87.1 \%$ & $99.2 \%$ & $97.1 \%$ & $96.2 \%$ & $96.4 \%$ \\
\hline & & & \multicolumn{2}{|c|}{$\begin{array}{l}\text { RDC-A According to Expert } \\
\text { Interview }\end{array}$} & \multirow[t]{2}{*}{$x^{2}$} & \multirow[t]{2}{*}{$\mathbf{P}$} & \multirow[t]{2}{*}{ Kappa Agreement } \\
\hline & & & -VE & +VE & & & \\
\hline \multirow[t]{4}{*}{ Agitation according to SMDS } & \multirow[t]{2}{*}{$-V E$} & $N$ & 138 & I & \multirow[t]{4}{*}{156.85} & \multirow[t]{4}{*}{$0.00 * *$} & \multirow[t]{4}{*}{0.95} \\
\hline & & $\%$ & 99.3 & 3.2 & & & \\
\hline & \multirow[t]{2}{*}{$+\mathrm{VE}$} & $N$ & 1 & 30 & & & \\
\hline & & $\%$ & 0.7 & 96.8 & & & \\
\hline \multicolumn{2}{|l|}{ Total } & $N$ & 139 & 31 & & & \\
\hline Validity & & & Sensitivity & Specificity & +VE Predictive & -VE Predictive & Accuracy \\
\hline & & & $96.8 \%$ & $99.3 \%$ & $96.7 \%$ & $99.2 \%$ & $98.9 \%$ \\
\hline & & & $\begin{array}{l}\text { Overall N } \\
\text { Interview }\end{array}$ & According to Expert & $\chi^{2}$ & $\mathbf{P}$ & Kappa Agreement \\
\hline & & & -VE & +VE & & & \\
\hline Overall mixity by SMDS & $-\mathrm{VE}$ & $N$ & 98 & 6 & 146.1 & $0.00 * *$ & 0.91 \\
\hline & & $\%$ & 98.0 & 8.6 & & & \\
\hline & $+\mathrm{VE}$ & $N$ & 2 & 64 & & & \\
\hline & & $\%$ & 2.0 & 91.4 & & & \\
\hline Total & & $\mathrm{N}$ & 100 & 70 & & & \\
\hline Validity & & & Sensitivity & Specificity & $+V E$ Predictive & -VE Predictive & Accuracy \\
\hline & & & $91.4 \%$ & $98.0 \%$ & $96.9 \%$ & $94.2 \%$ & $95.2 \%$ \\
\hline
\end{tabular}

Note: **Highly significant.

However, it limits itself to the DSM-defined manic symptoms and neglects the most common excitatory symptoms. One other self-rated scale has been developed for mixed depression, the CUDOS-M. ${ }^{41}$ It differs from our scale in that it assesses only the DSM-5 mixed specifier. Again, it neglects the most common agitation and other excitatory symptoms. Defining the basic nature of "psychic depressive states", Griesinger ${ }^{42}$ stated that the basic nature that underlies the psychic depressive states is not inactivity and suppression of the psychic processes. He assumed that the cause of such states is mostly an intense state of irritation of the brain and excitation of the psychic processes. Following 
Griesinger's use of the phrase "excitation of the psychic processes", and given what is really encountered in clinical practice, we suggest, just like others, ${ }^{24}$ that mixed symptoms of depression might be better called excitatory rather than hypo/manic symptoms. Patients with excitatory (mixed) depression lack expansiveness and easy performance of activities. They are tormented by their psychic pain and unable to perform activities. ${ }^{24}$ However, we are not inclined to abandon the DSM-5-defined mixed specifier or assume it is nothing but a kind of mixed hypomania as proposed elsewhere. $^{24}$ Also, one cannot claim, as it is the case in expansive mixity, that excitatory mixity could be a marker of bipolarity. Instead, the negative impact of antidepressants on such symptoms, be they excitatory or expansive, is what we insist on and develop the scale to guard against. The same might be argued for psychomotor agitation which is represented in the first subscale. The utility of the concept of psychomotor agitation as a mixed feature is supported by the negative impact of antidepressants on it and by being a precursor to suicidality related or unrelated to antidepressants. $^{35,43-46}$ Based on the notion that a definition of mixed depression which will better show the impact of treatment is the definition of choice in clinical practice, ${ }^{44} \mathrm{~K}-\mathrm{DMX}$ and RDC-A should be considered important and clinically relevant mixed features in depression and the development of a scale as an aid to capture them is worthwhile.

\section{Limitations}

1. The assessment was cross-sectional; thus, we did not examine the long-term stability of the scale.

2. As the study was conducted in a sample of outpatients, replication in other samples with different clinical characteristics might be warranted.

3. Taking in consideration the patients' extreme suffering as well as the reported dramatic, unique and fast improvement on Olanzapine alone in such mixed cases, ${ }^{22,36,47}$ we did not delay the use of Olanzapine at the expense of assessing test-retest reliability.

\section{Conclusion}

The SMDS showed good psychometric properties with good internal consistency, high sensitivity, specificity, positive predictive value and negative predictive value. It demonstrated a two-factor structure; one for mixity without psychomotor agitation and another for psychomotor agitation.
Overall, SMDS can be considered a useful instrument for measuring the non-DSM mixed features in UP as proposed by Koukopoulos. We recommend the routine use of our scale in all apparently depressed patients in order to screen for a possible clinically relevant mixity. In addition, we recommend conducting further studies on what Koukopoulos named excitatory symptoms. We hypothesize that such excitatory symptoms could constitute a third polarity or, at the very least, fall on a continuum between inhibited/retarded depression and expansive hypo/mania.

\section{Acknowledgments}

We would like to show our gratitude to professor Jules Angst, for sharing his pearl of wisdom with us during the course of this research. He has provided insight and expertise that greatly assisted our study. We also thank Dr Abu Bakr Omar, for his unfailing patient assistance with the manuscript preparation. Last but not least, we greatly appreciate the help of our patients and their families.

\section{Disclosure}

Dr Vieta has received grants and served as consultant, advisor or CME speaker for the following entities: ABBiotics, Abbott, Allergan, Angelini, AstraZeneca, BristolMyers Squibb, Dainippon Sumitomo Pharma, Farmindustria, Ferrer, Forest Research Institute, Galenica, Gedeon Richter, Glaxo-Smith-Kline, Janssen, Lundbeck, Otsuka, Pfizer, Roche, Sage, Sanofi-Aventis, Servier, Shire, Sunovion, Takeda, the Brain and Behaviour Foundation, the Generalitat de Catalunya (PERIS), the Spanish Ministry of Science, Innovation and Universities (CIBERSAM), EU Horizon 2020, and the Stanley Medical Research Institute. The authors report no other conflicts of interest in this work.

\section{References}

1. American Psychiatric Association. Diagnostic and statistical manual of mental disorders (DSM-5); 2019. Available from: www.dsm5.org. Accessed September 7, 2020.

2. Koukopoulos A, Sani G, Nassir S. Mixed features of depression: why DSM-5 is wrong (and so was DSM-IV). Br J Psychiatry. 2013;203 (2013):3-5. doi:10.1192/bjp.bp.112.124404

3. Koukopoulos A, Faedda G, Proietti R, D'Amico S, de Pisa E, Simonetto C. Mixed depressive syndrome. Encephale. 1992;18 (SpecNo1):19-21.

4. Maj M, Pirozzi R, Magliano L, Bartoli L. Agitated depression in bipolar I disorder: prevalence, phenomenology, and outcome. Am J Psychiatry. 2003;160(12):2134-2140. doi:10.1176/appi.ajp.160.12. 2134 
5. Spitzer RL, Endicott J, Robins E. Research Diagnostic Criteria $(R D C)$. New York: Biometrics Research Evaluation Center, New York State Psychiatric Institute; 1978.

6. Benazzi F. Depressive mixed state frequency: age/gender effects. Psychiatry Clin Neurosci. 2002;56(5):537-543. doi:10.1046/j.14401819.2002.01051.x

7. Takeshima M, Oka T. "DSM-5-defined 'mixed features' and Benazzi's mixed depression: which is practically useful to discriminate bipolar disorder from unipolar depression in patients with depression?". Psychiatry Clin Neurosci. 2015;69(2):109-116. doi: $10.1111 / \mathrm{pen} .12213$

8. Koukopoulos A, Koukopolos A. Agitated depression as a mixed state and the problem of melancholia. Psychiatr Clin North Am. 1999;22 (3):547-564. doi:10.1016/S0193-953X(05)70095-2

9. Akiskal HS. The distinctive mixed states of bipolar I, II, and III. Clin Neuropharmacol. 1992;15:632A-633A. doi:10.1097/00002826199201001-00327

10. Bourgeois M, Verdoux H, Mainard CH. Dysphoric mania and mixed states. Encephale. 1995;21:21-32.

11. Dell'Osso L, Placidi GF, Nassi R, Freer P, Cassano GB, Akiskal HS. The manic-depressive mixed state: familial, temperamental and psychopathologic characteristics in 108 female inpatients. Eur Arch Psychiatry Clin Neurosci. 1991;240(4-5):234-239. doi:10.1007/ bf02189532

12. Himmelhoch JM, Coble P, Kupfer KJ, Ingenito J. Agitated psychotic depression associated with severe hypomanic episodes: a rare syndrome. Am J Psychiatry. 1976;133:765-771. doi:10.1176/ ajp.133.7.765

13. Perugi G, Akiskal HS, Micheli C, et al. Clinical subtypes of bipolar mixed states: validating a broader European definition in 143 cases. $J$ Affect Disord. 1997;43(3):169-180. doi:10.1016/s0165-0327(97)01446-8

14. Koukopoulos A, Girardi P, Proietti R, Gaston A. Diagnostic and therapeutic considerations on agitated depression understood as a mixed affective state. Minerva Psychiatry. 1989;30:283-286.

15. Swann AC, Secunda SK, Katz MM, et al. Specificity of mixed affective states: clinical comparison of dysphoric mania and agitated depression. J Affect Disord. 1993;28(2):81-89. doi:10.1016/01650327(93)90036-j

16. Stahl S, Morrissette D, Faedda G, Fava M, Goldberg J, Keck P. Guidelines for the recognition and management of mixed depression. CNS Spectr. 2017;22(2):203-219. doi:10.1017/ S1092852917000165

17. Sani G, Vöhringer PA, Napoletano F, et al. Koukopoulos' diagnostic criteria for mixed depression: a validation study. J Affect Disord. 2014b;164:14-18. doi:10.1016/j.jad.2014.03.054

18. Kendell R, Jablensky A. Distinguishing between the validity and utility of psychiatric diagnoses. Am J Psychiatry. 2003;160(1):4-12. doi:10.1176/appi.ajp.160.1.4

19. Benazzi F. Agitated depression: a valid depression subtype? Prog Neuropsychopharmacol Biol Psychiatry. 2004;28(8):1279-1285. doi:10.1016/j.pnpbp.2004.06.018

20. Benazzi F. Reviewing the diagnostic validity and utility of mixed depression (depressive mixed states). Eur Psychiatry. 2008;23 (1):40-48. doi:10.1016/j.eurpsy.2007.07.003

21. Koukopoulos A, Sani G, Koukopoulos AE, Manfredi G, Pacchiarotti I, Girardi P. Melancholia agitata and mixed depression. Acta Psychiatr Scand. 2007;115(Suppl. 433):50-57. doi:10.1111/ j.1600-0447.2007.00963

22. Koukopoulos A, Sani G, Albert MJ, et al. Agitated depression: spontaneous and induced. In: Goodwin FK, Marneros A, editors. Bipolar Disorder. Cambridge: Cambridge University Press; 2004.

23. Akiskal HS, Mallya G. Criteria for the "soft" bipolar spectrum: treatment implications. Psychopharmacol Bull. 1987;23:68-73.

24. Koukopoulos A, Sani G. DSM-5 criteria for depression with mixed features: a farewell to mixed depression. Acta Psychiatr Scand. 2014;129(1):4-16. doi:10.1111/acps.12140
25. Angst J, Azorin JM, Bowden CL, et al. Prevalence and characteristics of undiagnosed bipolar disorders in patients with a major depressive episode: the BRIDGE study. Arch Gen Psychiatry. 2011;68 (8):791-798. doi:10.1001/archgenpsychiatry.2011.87

26. Montgomery SA, Asberg M. A new depression scale designed to be sensitive to change. $B r \quad J$ Psychiatry. 1979;134(4):382-389. doi:10.1192/bjp.134.4.382

27. Williams JBW, Terman M, Link MJ, Amira L, Rosenthal NE. Hypomania Interview Guide (Including Hyperthymia). Current Assessment Version (HIGH-C). Norwood, NJ: Clinical Assessment Tools Packet, Center for Environmental Therapeutics; 1994.

28. Benazzi F. Defining mixed depression. Prog Neuro Psychopharmacol Biol Psychiatry. 2008;32(4):932-939. doi:10.1016/j.pnpbp.2007.12.019

29. Sani G, Vöhringer PA, Barroilhet SA, Koukopoulos AE, Ghaemi SN. The Koukopoulos Mixed Depression Rating Scale (KMDRS): an International Mood Network (IMN) validation study of a new mixed mood rating scale. $J$ Affect Disord. 2018;232:9-16. doi:10.1016/j.jad.2018.01.025

30. Alexopoulos GS, Abrams RC, Young RC, Shamoian CA. Cornell scale for depression in dementia. Biol Psychiatry. 1988;23 (3):271-284. doi:10.1016/0006-3223(88)90038-8

31. Kraepelin E. Manic-Depressive Insanity and Paranoia. Edinburgh: E\&S Livingstone; 1899/1921.

32. Akiskal HS, Benazzi F. Family history validation of the bipolar nature of depressive mixed states. $J$ Affect Disord. 2003;73:113-122. doi:10.1016/s0165-0327(02)00330-0

33. Benazzi F. Age at onset of bipolar II depressive mixed state. Psychiatry Res. 2001;103(2-3):229-235. doi:10.1016/s01651781(01)00258-x

34. Sato T, Bottlender R, Schroter A, Moller H-J. Frequency of manic symptoms during a depressive episode and unipolar 'depressive mixed state' as bipolar spectrum. Acta Psychiatr Scand. 2003;107 (4):268-274. doi:10.1034/j.1600-0447.2003.00051.x

35. Ducrey S, Gex-Fabry M, Dayer A, et al. A retrospective comparison of inpatients with mixed and pure depression. Psychopathology. 2004;36(6):292-298. doi:10.1159/000075187

36. Shahin I. Shahin mixed depression scale (SMDS); a novel tool that captures unofficial mixity in depression. Poster presented at IFMAD 2017; December 14-16; 2017; Madrid, Spain.

37. Benazzi F. Family history validation of a definition of mixed depression. Compr Psychiatry. 2005;46(3):159-166. doi:10.1016/j. comppsych.2004.07.034

38. Benazzi F. Bipolar family history of the hypomanic symptoms and dimensions of mixed depression. Compr Psychiatry. 2005;46 (6):399-404. doi:10.1016/j.comppsych.2005.02.002

39. Maj M, Pirozzi R, Magliano L, Fiorillo A, Bartoli L. Agitated 'unipolar' major depression: prevalence, phenomenology, and outcome. $J$ Clin Psychiatry. 2006;67(05):712-719. doi:10.4088/jcp.v67n0504

40. Cavanagh J, Schwannauer M, Power M, Goodwin GM. A novel scale for measuring mixed states in bipolar disorder. Clin Psychol Psychother. 2009;16(6):497-509. doi:10.1002/cpp.633

41. Zimmerman M, Chelminski I, Young D, Dalrymple K, Martinez JH. A clinically useful self-report measure of the DSM-5 mixed features specifier of major depressive disorder. $J$ Affect Disord. 2014;168:357-362. doi:10.1016/j.jad.2014.07.021

42. Griesinger W. Pathologie und Therapie der psychischen Krankheiten. 2nd ed. Stuttgart: Adolf Krabbe Verlag; 1861.

43. Balazs J, Benazzi F, Rihmer Z, Rihmer A, Akiskal KK, Akiskal HS. The close link between suicide attempts and mixed (bipolar) depression: implications for suicide prevention. J Affect Disord. 2006;91 (2-3):133-138. doi:10.1016/j.jad.2005.12.049

44. Benazzi F. Suicidal ideation and depressive mixed states. Psychother Psychosom. 2005;74(1):61-62. doi:10.1159/000082029

45. Koukopoulos A, Albert MJ, Sani G, Koukopoulos AE, Girardi P. Mixed depressive states: nosologic and therapeutic issues. Int Rev Psychiatry. 2005;17(1):21-37. doi:10.1080/09540260500064744 
46. Perlis RH, Beasley CM Jr, Wines JD Jr, et al. Treatment-associated suicidal ideation and adverse effects in an open, multicenter trial of fluoxetine for major depressive episodes. Psychother Psychosom. 2007;76(1):40-46. doi:10.1159/000096363
47. Parker G. Olanzapine augmentation in the treatment of melancholia: the trajectory of improvement in rapid responders. Int Clin Psychopharmacol. 2002;17(2):87-89. doi:10.1097/00004850-20020 3000-00008

\section{Publish your work in this journal}

Neuropsychiatric Disease and Treatment is an international, peerreviewed journal of clinical therapeutics and pharmacology focusing on concise rapid reporting of clinical or pre-clinical studies on a range of neuropsychiatric and neurological disorders. This journal is indexed on PubMed Central, the 'PsycINFO' database and CAS, and is the official journal of The International Neuropsychiatric Association (INA). The manuscript management system is completely online and includes a very quick and fair peer-review system, which is all easy to use. Visit http://www.dovepress.com/testimonials.php to read real quotes from published authors.

Submit your manuscript here: https://www.dovepress.com/neuropsychiatric-disease-and-treatment-journal 